\title{
TILTMETER OBSERVATIONS FROM DOAKE ICE RUMPLES, RONNE ICE SHELF, ANTARCTICA \\ (Abstract)
}

by

A.M. Smith

(British Antarctic Survey, Natural Environment Research Council, High Cross, Madingley Road, Cambridge CB3 OET, England)

\section{ABSTRACT}

New tiltmeter data from Doake Ice Rumples on Ronne Ice Shelf are presented. The tiltmeters detected flexing of the ice shelf close to the grounding line, due to tidal forces. In earlier studies on Rutford Ice Stream, flow was from grounded ice into the floating ice shelf. In contrast, the area studied on Ronne Ice Shelf exhibits flow from the ice shelf on to grounded ice rumples.

The data span $5 \mathrm{~km}$ of the up-stream ice shelf and much of the grounded ice. Approximately $30 \mathrm{~d}$ of continuous tilt data are available for one site on the ice shelf. Analysis of this record can determine the dominant tidal frequencies present.

A number of shorter records cover periods normally of a few days. These were obtained from sites both up-stream and down-stream of the long-term site. They have been used to investigate the variation in tilt amplitude with distance from the grounding line.
The approximate position of the grounding line was located from the position of strand cracks and by using surface-elevation and ice-thickness data. The tiltmeters helped to confirm this position. Over grounded ice, tidal flexing is clearly present up to about $2 \mathrm{~km}$ from the grounding line. Beyond this it appears to be absent. The signal recorded by tiltmeters on grounded ice farther than $2 \mathrm{~km}$ from the grounding line is attributed, at present, to a temperature dependency of the tiltmeters.

The flexing of ice shelves at tidal frequencies has previously been treated as an elastic problem. Available models which use beam theory require the use of a timedependent function and a reduced "effective" ice thickness in the elastic modulus. On preliminary analysis, data from the ice shelf and grounding line of Doake Ice Rumples appear to be consistent with these theories. More detailed analysis and interpretation is required in order to confirm the level of agreement and to determine possible variations due to the "reversed" nature of the flow direction.

\section{DEVELOPMENT OF THE CRYSTAL STRUCTURE WITHIN THE LAW DOME ICE CAP, ANTARCTICA}

\author{
(Abstract) \\ by \\ Neal W. Young \\ (Australian Antarctic Division, Channel Highway, Kingston, Tasmania 7050, \\ Australia)
}

\section{ABSTRACT}

Fourteen shallow and medium-depth cores have been drilled from the Law Dome ice cap, between the summit and the coast near Casey Station. Measurements of their crystal and other physical properties are reviewed briefly. The variations along the cores in crystal size, orientation, fabric type and strength, and bubble dimensions, are used to define the internal structure of the ice cap locally at the bore-hole sites. Surveys of bore-hole deformation and the shape and movement of the ice cap are used to define relations between the structure and the variables: stress, temperature, strain-rate and accumulated strain. The relations and the survey data are incorporated in a numerical model in order to deduce the internal structure of the ice cap along a flow line linking the bore-hole sites. The results of the model in turn depend on the crystal anisotropy of the calculated structure.

The main results are provided by the medium-depth bore holes located at the summit, near the margin, and about half-way along the flow line. The major features of the internal structure are determined by the predominant shear deformation in the ice cap. There is horizontal continuity in the properties and structure within the group of bore holes near the margin of the ice cap. There are distinct differences, between the coastal and the inland ice cores, in the changes in properties with depth. Near the margin a strong single-maximum fabric develops within the upper $60 \%$ of the ice thickness; crystal size initially increases with depth, then shows a marked decrease at about $50 \%$ thickness. For the inland cores, a strong single-maximum fabric also develops, but at a greater total depth and a much shallower fraction of the thickness. A similar decrease in crystal size was not observed.

The broad-scale trends of the properties are reproduced by the model. The finer-scale deviations in the properties can be explained by the effects of longitudinal strain and of past changes in surface conditions, such as the effect of surface melting. A complex stress distribution, related to flow over rough bedrock, needs to be invoked to explain the pronounced multi-layer structure in the lower part of the ice cores from near the margin. A series of time lines is modelled, following the flow along the ice-particle trajectories, to produce the stress, temperature and deformation histories of the ice in the cores. These provide the basic data for a reconstruction of past changes in the ice cap. 